\title{
25 Research Soure \\ Validation of The 2018 FIGO Staging System for Predicting The Prognosis of Patients With Stage IIIC Cervical Cancer
}

\section{Xingtao Long}

Chongqing University cancer hospital

Qi Zhou ( $\square$ qizhou9128@163.com )

Chongqing University cancer hospital https://orcid.org/0000-0001-5673-4263

Dongling Zou

Chongqing University cancer hospital

Dong Wang

Chongqing University cancer hospital

Jingshu Liu

Chongqing University cancer hospital

\section{Yuemei Chen}

Chongqing University cancer hospital

\section{Research Article}

Keywords: International Federation of Gynecology and Obstetrics, FIGO, Staging, Cervical cancer, prognosis.

Posted Date: September 13th, 2021

DOI: https://doi.org/10.21203/rs.3.rs-708694/v1

License: @ (i) This work is licensed under a Creative Commons Attribution 4.0 International License. Read Full License 


\section{Abstract}

Purpose We aimed to validate the prognostic performance of the 2018 International Federation of Gynecology and Obstetrics(FIGO) IIIC staging system for patients with cervical cancer.

Methods We conducted a retrospective analysis of patients with stage III cervical cancer according to the 2018 FIGO staging system who received standardized treatment from January 2011 to December 2014.

Results Multivariable analysis revealed that stage IIIC1 was not significantly associated with increased risk of death compared with stages IIIA (hazard ratio [HR] = 1.432; 95\% confidence interval [Cl]: 0.867 to $2.366 ; P=$ $0.161)$ and IIIB (HR $=1.261 ; 95 \% \mathrm{Cl}: 0.871$ to $1.827 ; P=0.219)$. Stage IIIC2 was an independent indicator of increased risk of mortality compared with stages IIIA (HR $=2.958 ; 95 \% \mathrm{Cl}: 1.757$ to $4.983 ; P<0.001)$ and IIIIB $(\mathrm{HR}=2.606 ; 95 \% \mathrm{Cl}: 1.752$ to $3.877 ; P<0.001)$. We stratified patients with stage IIIC1 according to T stage and compared survival outcomes. Stage IIIC1 (T1) was associated with longer 5-year overall survival (OS) compared with stages IIIA $(P=0.004)$ or IIIB $(P<0.001)$. An optimal cut-off value $(=2)$ was established for predicting the prognosis of stage IIIC1 $\mathrm{p}(\mathrm{T} 1 / \mathrm{T} 2 \mathrm{a})$, which was associated with the number of pelvic lymph nodes metastases (PLNMs). Patients with stage IIIC1pN1-2 experienced longer 5-year OS compared those with stages IIIA $(P=0.01)$ or IIIB $(P<0.001)$.

Conclusion Patients with stage IIIC1 cervical cancer exhibited heterogeneous clinical characteristics reflecting their variable prognoses, depending on T-stage and the extent of PLNMs

\section{Introduction}

In 2018, approximately 570000 cases of cervical cancer and 311000 deaths from the disease in the worldwide [1]. Cervical cancer is the the most frequent malignancy of the female genital tract in China [2]. Unlike most solid tumors, cervical cancer has been historically clinically staged and is now most widely staged using the International Federation of Gynecology and Obstetrics (FIGO) system, which is convenient and reliable, and includes the most powerful prognostic factors [3-5]. However, with the rapid development of modern imaging technology, and surgical-pathological techniques, the deficiencies of the FIGO staging system are more prominent [6-7]. In October 2018, a revised FIGO classification for cervical cancer was published subsequent to the 22nd FIGO Annual Conference [8]. The major revision to the 2018 FIGO stage III classification is the incorporation of nodal status determined using radiological imaging or pathological assessment [8]. For example, stages IIIC1 and IIIC2 include only metastatic pelvic lymph nodes or para-aortic lymph node metastasis, respectively [8]. Although lymph node metastasis is associated with high risk for worse survival [9], the 2018 FIGO classification of patients with stage IIIC does not include the size and extent of the primary tumor. Moreover, stratification of all patients with positive lymph nodes as stage IIIC yields a clinically heterogeneous group, causing clinicians to question the reliability of following 2018 FIGO [10-12].

Consequently, the extent of stage migration and changes in survival outcomes are largely unknown.The objective of the present study was to retrospectively validate the prognostic performance of the 2018 FIGO staging system for stage IIIC cervical cancer and to conduct risk stratification incorporating additional prognostic factors. 


\section{Materials And Methods}

\section{Patients}

The clinicopathological characteristics and other relevant information (recorded between January 2011 and December 2014) were retrieved from the electronic medical record system of Chongqing University Cancer Hospital, Chongqing, China, and its Ethics Committee approved this study ( project number: 2019[177] ). Informed consent for using medical information for scientific purposes was obtained from all subjects. The inclusion criteria were as follows: i) patients aged $\geq 18$ years or $\leq 85$ years; ii) histologically confirmed cervical squamous cell carcinoma, adenocarcinoma, or adenosquamous cell carcinoma; iii) diagnosis of 2018 FIGO stage III cervical cancer; and iv) patients who received standard treatment and completed the main recommended treatments. The exclusion criteria were as follows: i) unknown lymph node status; ii) history of combined malignancies; iii) unknown tumor size; iv) treatment not administered after recurrence. The diagnostic criteria for stage IIICr were as follows: i) lymphadenectasis, short diameter $\geq 1 \mathrm{~cm}$ confirmed using $\mathrm{MRI} / \mathrm{CT}$ and two experts imaging diagnosis of lymph node metastasis, and ii) lymph node metastases confirmed using PET-CT. Overall survival (OS) was defined as the time from the date of initial diagnosis to death or to the last follow-up. Follow-up deadline: October 25, 2019, median follow-up: 58.96 months (range, 7-92 months). In accordance with the journal's guidelines, we will provide our data for the reproducibility of this study in other centers if such is requested.

\section{Treatments}

All patients received standard first-line regimens as follows: i) surgery comprising radical hysterectomy and bilateral pelvic lymphadenectomy with or without paraortic lymphadenectomy, using standard open or minimally invasive surgery; adjuvant treatment after radical hysterectomy according to the guidelines and clinical practic; ii) radical radiochemotherapy with or without consolidation chemotherapy. Relapsed patients received comprehensive treatment, including surgery, chemotherapy, radiation therapy, targeted therapy and so on.

\section{Statistical Analysis}

Statistical analysis was performed using SPSS 25 and GraphPad Prism 6.01 software. Numerical values are presented as rates. Multigroup comparisons were performed using the chi-squared or Kruskal-Wallis $\mathrm{H}$ test, as appropriate. Survival analysis was conducted using the Kaplan-Meier method, and the data were compared using the log-rank test. Multivariable analysis was performed using a cox proportional hazard regression model (variables with $P \leq 0.1$ were included). Differences with $P<0.05$ (two-tailed) were considered significant. SPSS was used to calculate Bonferroni-corrected P values for pairwise comparisons.

\section{Results}

\section{Clinical Characteristics}

Between 2011 and 2014, 503 patients with cervical cancer were clinically staged as 2018 FIGO stage III, in accordance with the inclusion criteria. We excluded 85 patients ( 27 for unfinised treatment, 3 combined with 
other malignant tumors, 32 without imaging finding of prompting lymph node or tumor size, 23 no treatment was given after recurrence), leaving 418 patients that were appropriate for analysis (Fig. 1). These patients were diagnosed with stages IIII $(n=42,10.0 \%)$, IIIB $(n=120,28.7 \%)$, IIIC1 $(n=190,45.5 \%)$, or IIIC2 $(n=66$, $15.8 \%)$. Patients with stage IIIC1 were younger than those with stage IIIA $(P<0.001)$. The histological type, cell differentiation, tumor size, type of radiotherapy, and administration of consolidation chemotherapy among the different stages were balanced (each, $P>0.05$ ). The differences between patients with stage IIIC1 or IIIC2 who underwent radical hysterectomy, minimally invasive surgery, or neoadjuvant chemotherapy were balanced (each $P>0.05$ ) (Table 1). Pelvic lymphadenectomy was exclusively administered to 106 patients, and the median number of pelvic lymph nodes removed was 25 (range, 11-42). Sixty-two patients underwent pelvic and para-aortic lymphadenectomy, and the median number of para-aortic lymph nodes removed was 5 (range, 2-11). 
Table 1

Patient demographics of 2018 FIGO stage $₫$ cervical cancer

\begin{tabular}{|c|c|c|c|c|c|}
\hline \multirow[t]{3}{*}{ Characteristic } & Stage $\llbracket \mathbf{A}$ & Stage 『B & Stage $\mathbb{C} 1$ & Stage $\mathbb{C} 2$ & \multirow[t]{3}{*}{$p$-value } \\
\hline & $N=42$ & $N=120$ & $N=190$ & $N=66$ & \\
\hline & $(10.0 \%)$ & $(28.7 \%)$ & $(45.5 \%)$ & $(15.8 \%)$ & \\
\hline Age(years) & & & & & 0.003 \\
\hline$<65$ & $30(71.4 \%)$ & $98(81.7 \%)$ & $174(91.6 \%)$ & $56(84.8 \%)$ & \\
\hline$\geq 65$ & $12(28.6 \%)$ & $22(18.3 \%)$ & $16(8.4 \%)$ & $10(15.2 \%)$ & \\
\hline Histology & & & & & 0.680 \\
\hline Squamous & $29(69.0 \%)$ & $96(80.0 \%)$ & $152(80.0 \%)$ & $49(74.3 \%)$ & \\
\hline Adenocarcinoma & $7(16.7 \%)$ & $13(10.8 \%)$ & $23(12.1 \%)$ & $8(12.1 \%)$ & \\
\hline Adenosquamous Carcinoma & $6(14.3 \%)$ & $11(9.2 \%)$ & $15(7.9 \%)$ & $9(13.6 \%)$ & \\
\hline Grade & & & & & 0.279 \\
\hline 3 & $6(14.3 \%)$ & $27(22.5 \%)$ & $37(19.4 \%)$ & $11(16.7 \%)$ & \\
\hline 2 & $26(61.9 \%)$ & $68(56.7 \%)$ & $126(66.3 \%)$ & 46 (69.6\%) & \\
\hline 1 & $5(11.9 \%)$ & $5(4.2 \%)$ & $6(3.2 \%)$ & $4(6.1 \%)$ & \\
\hline Unknown & $5(11.9 \%)$ & $20(16.6 \%)$ & $21(11.1 \%)$ & $5(7.6 \%)$ & \\
\hline Tumor size(cm) & & & & & 0.727 \\
\hline$<4$ & $21(50.0 \%)$ & $49(40.8 \%)$ & $87(45.8 \%)$ & 30 (45.5\%) & \\
\hline$\geq 4$ & $21(50.0 \%)$ & $71(59.2 \%)$ & $103(54.2 \%)$ & $36(54.5 \%)$ & \\
\hline \multicolumn{6}{|l|}{ Neoadjuvant chemotherapy } \\
\hline Yes & 0 & 0 & $51(26.8 \%)$ & $21(31.8 \%)$ & 0.439 \# \\
\hline No & 42 & 120 & $139(73.2 \%)$ & $45(68.2 \%)$ & \\
\hline Radical Hysterectomy & & & & & 0.319 \# \\
\hline Yes & 0 & 0 & $128(67.4 \%)$ & $40(60.6 \%)$ & \\
\hline No & 42 & 120 & $62(32.6 \%)$ & $26(39.4 \%)$ & \\
\hline Minimally invasive surgery & & & & & 0.524 \# \\
\hline Yes & 0 & 0 & $23(18.0 \%)$ & $9(22.5 \%)$ & \\
\hline No & 42 & 120 & 105 (82.0\%) & 31 (77.5\%) & \\
\hline
\end{tabular}

3- DCRT, 3-Dimensional Conformal Radiotherapy; IMRT, Intensity Modulated Radiotherapy; \# Stage $\llbracket C 1$ vs $\bigotimes \mathrm{C} 2$ 


\begin{tabular}{|c|c|c|c|c|c|}
\hline \multirow[t]{3}{*}{ Characteristic } & Stage $\llbracket A$ & Stage 邓B & Stage $\mathbb{X C 1}$ & Stage $\mathbb{X C 2}$ & \multirow[t]{3}{*}{$p$-value } \\
\hline & $N=42$ & $N=120$ & $N=190$ & $N=66$ & \\
\hline & $(10.0 \%)$ & $(28.7 \%)$ & (45.5\%) & $(15.8 \%)$ & \\
\hline Radiotherapy & & & & & 0.555 \\
\hline 3-DCRT & $19(45.2 \%)$ & $48(40.0 \%)$ & $88(46.3 \%)$ & $25(37.9 \%)$ & \\
\hline IMRT & $23(54.8 \%)$ & $72(60.0 \%)$ & $102(53.7 \%)$ & $41(62.1 \%)$ & \\
\hline Consolidation chemotherapy & & & & & 0.765 \\
\hline Yes & $31(73.8 \%)$ & $89(74.2 \%)$ & $147(77.4 \%)$ & 47 (71.2\%) & \\
\hline No & 11 (26.2\%) & $31(25.8 \%)$ & $43(22.6 \%)$ & 19 (28.8\%) & \\
\hline
\end{tabular}

\section{Survival Outcomes}

The 5 -year OS rates were $54.1 \%$ for stage IIIC1 vs $43.3 \%$ for stage IIIA vs $40.6 \%$ for stage IIIB vs $23.1 \%$ for stage IIIC2 $(P<0.001)$ (Fig. 2a). The 5-year OS rate in patients with stage IIIC1 was higher, but not statistically significant compared with stages IIIA $(P=0.484)$ and IIIB $(P=0.042)$. Stage IIIC2 cervical cancer patients experienced significantly shorter OS compared with those with stage IIIC1, IIIA, or IIIB (each, $P<0.001$ ). Increasing tumor size was associated with shorter 5-year OS rates as follows: $69.4 \%$, tumor diameter $<4 \mathrm{~cm}$; $36.5 \%$, tumor diameter $\geq 4 \mathrm{~cm}(P<0.001)$. Patients undergoing radical hysterectomy had a significantly higher 5 -year OS rate (72.1\%) compared with those who did not (48.3\%) $(P<0.001)$; However, the histological type, cell differentiation, neoadjuvant chemotherapy, type of radiotherapy, minimally invasive surgery, or consolidation chemotherapy did not affect the 5-year OS rate (each, $P>0.05$ ) (Table 2). Variables with $P \leq 0.1$ in the univariate analysis were included in the multivariable analysis, the results of which are as follows: 2018 FIGO stage III was an independent risk factor. Stage IIIC2 was significantly associated with an increased risk of mortality compared with stage IIIC1 ((hazard ratio HR $=2.066 ; 95 \%$ confidence interval [CI]: 1.438 to 2.969; $P<0.001$ ), stage IIIB (HR=2.606; 95\% Cl: 1.752 to $3.877 ; P<0.001)$, and stage IIIA (HR=2.958; $95 \%$ Cl: 1.757 to $4.983 ; P<0.001)$. Stage IIIC1 was not significantly associated with an increased risk of mortality compared with stage IIIA (HR $=1.432 ; 95 \% \mathrm{Cl}: 0.867$ to $2.366 ; P=0.161)$, and stage IIIB (HR $=1.261 ; 95 \% \mathrm{Cl}: 0.871$ to $1.827 ; P=0.219$ ) (Table 2). 
Table 2

Univariate and multivariable analysis for survival in stage III cohort

\begin{tabular}{|c|c|c|c|c|c|c|c|c|c|}
\hline \multirow[t]{2}{*}{ Characteristic } & \multirow[t]{2}{*}{ No. } & \multicolumn{2}{|l|}{$\begin{array}{l}\text { Survival } \\
\text { rate (\%) }\end{array}$} & \multicolumn{2}{|c|}{$\begin{array}{l}\text { Multivariable } \\
\text { (vs stage } \llbracket \mathrm{A} \text { ) }\end{array}$} & \multicolumn{2}{|c|}{$\begin{array}{l}\text { Multivariable } \\
\text { (vs stage 『B) }\end{array}$} & \multicolumn{2}{|c|}{$\begin{array}{l}\text { Multivariable } \\
\text { (vs stage } \bowtie C 1 \text { ) }\end{array}$} \\
\hline & & 5-year & $\begin{array}{l}P \\
\text { value }\end{array}$ & $\begin{array}{l}\text { HR } \\
(95 \% \mathrm{Cl})\end{array}$ & $\begin{array}{l}P \\
\text { value }\end{array}$ & $\begin{array}{l}\text { HR } \\
(95 \% \mathrm{Cl})\end{array}$ & $\begin{array}{l}P \\
\text { value }\end{array}$ & $\begin{array}{l}\text { HR } \\
(95 \% \mathrm{Cl})\end{array}$ & $\begin{array}{l}P \\
\text { value }\end{array}$ \\
\hline Age(years) & & & 0.806 & & & & & & \\
\hline$<65$ & 358 & 46.4 & & & & & & & \\
\hline$\geq 65$ & 60 & 39.6 & & & & & & & \\
\hline Histology & & & 0.402 & & & & & & \\
\hline Squamous & 326 & 45.8 & & & & & & & \\
\hline Adenocarcinoma & 51 & 42.9 & & & & & & & \\
\hline Adenosquamous & 41 & 34.6 & & & & & & & \\
\hline Grade & & & 0.481 & & & & & & \\
\hline 3 & 81 & 47.4 & & & & & & & \\
\hline 2 & 266 & 46.0 & & & & & & & \\
\hline 1 & 20 & 48.0 & & & & & & & \\
\hline Unknown & 51 & 44.4 & & & & & & & \\
\hline FIGO stage & & & $\begin{array}{l}< \\
0.001\end{array}$ & & & & & & \\
\hline$\nabla \mathrm{A}$ & 42 & 43.3 & & 1.000 & & $\begin{array}{l}0.881 \\
(0.551- \\
1.408)\end{array}$ & 0.532 & $\begin{array}{l}0.698 \\
(0.423- \\
1.154)\end{array}$ & 0.082 \\
\hline$\otimes B$ & 120 & 40.6 & & $\begin{array}{l}1.135 \\
(0.710- \\
1.814)\end{array}$ & 0.596 & 1.000 & & $\begin{array}{l}0.793 \\
(0.547- \\
1.148)\end{array}$ & 0.121 \\
\hline$\llbracket \mathrm{C} 1$ & 190 & 54.1 & & $\begin{array}{l}1.432 \\
(0.867- \\
2.366)\end{array}$ & 0.161 & $\begin{array}{l}1.261 \\
(0.871- \\
1.827)\end{array}$ & 0.219 & 1.000 & \\
\hline$\llbracket \mathrm{C} 2$ & 66 & 23.1 & & $\begin{array}{l}2.958 \\
(1.757- \\
4.983)\end{array}$ & $\begin{array}{l}< \\
0.001\end{array}$ & $\begin{array}{l}2.606 \\
(1.752- \\
3.877)\end{array}$ & $\begin{array}{l}< \\
0.001\end{array}$ & $\begin{array}{l}2.066 \\
(1.438- \\
2.969)\end{array}$ & $\begin{array}{l}< \\
0.001\end{array}$ \\
\hline
\end{tabular}




\begin{tabular}{|c|c|c|c|c|c|c|c|c|c|}
\hline \multirow[t]{2}{*}{ Characteristic } & \multirow[t]{2}{*}{ No. } & \multicolumn{2}{|l|}{$\begin{array}{l}\text { Survival } \\
\text { rate (\%) }\end{array}$} & \multicolumn{2}{|c|}{$\begin{array}{l}\text { Multivariable } \\
\text { (vs stage } \llbracket \mathrm{A} \text { ) }\end{array}$} & \multicolumn{2}{|c|}{$\begin{array}{l}\text { Multivariable } \\
\text { (vs stage 『B) }\end{array}$} & \multicolumn{2}{|c|}{$\begin{array}{l}\text { Multivariable } \\
\text { (vs stage } \otimes \mathrm{C} 1 \text { ) }\end{array}$} \\
\hline & & 5-year & $\begin{array}{l}P \\
\text { value }\end{array}$ & $\begin{array}{l}\text { HR } \\
(95 \% \mathrm{Cl})\end{array}$ & $\begin{array}{l}P \\
\text { value }\end{array}$ & $\begin{array}{l}\mathrm{HR} \\
(95 \% \mathrm{Cl})\end{array}$ & $\begin{array}{l}P \\
\text { value }\end{array}$ & $\begin{array}{l}\mathrm{HR} \\
(95 \% \mathrm{Cl})\end{array}$ & $\begin{array}{l}P \text {. } \\
\text { value }\end{array}$ \\
\hline Tumor size $(\mathrm{cm})$ & & & $<0.001$ & & & & & & \\
\hline$<4$ & 187 & 69.4 & & 1 & 0.001 & 1 & 0.001 & 1 & 0.001 \\
\hline \multirow[t]{2}{*}{$\geq 4$} & 231 & 36.5 & & 1.554 & & 1.554 & & 1.554 & \\
\hline & & & & $\begin{array}{l}(1.191- \\
2.029)\end{array}$ & & $\begin{array}{l}(1.191- \\
2.029)\end{array}$ & & $\begin{array}{l}(1.191- \\
2.029)\end{array}$ & \\
\hline $\begin{array}{l}\text { Neoadjuvant } \\
\text { chemotherapy }\end{array}$ & & & 0.271 & & & & & & \\
\hline Yes & 72 & 62.3 & & & & & & & \\
\hline No & 346 & 53.9 & & & & & & & \\
\hline $\begin{array}{l}\text { Radical } \\
\text { hysterectomy }\end{array}$ & & & $<001$ & & & & & & \\
\hline Yes & 168 & 72.1 & & 1 & $<.001$ & 1 & $<0.001$ & 1 & $<.001$ \\
\hline \multirow[t]{2}{*}{ No } & 250 & 48.3 & & 0.450 & & 0.450 & & 0.450 & \\
\hline & & & & $\begin{array}{l}(0.319- \\
0.635)\end{array}$ & & $\begin{array}{l}(0.319- \\
0.635)\end{array}$ & & $\begin{array}{l}(0.319- \\
0.635)\end{array}$ & \\
\hline $\begin{array}{l}\text { Minimally } \\
\text { invasive surgery }\end{array}$ & & & 0.752 & & & & & & \\
\hline Yes & 32 & 70.9 & & & & & & & \\
\hline No & 136 & 73.5 & & & & & & & \\
\hline Radiotherapy & & & 0.083 & & & & & & \\
\hline 3-DCRT & 180 & 46.5 & & 1 & 0.654 & 1 & 0.654 & 1 & 0.654 \\
\hline \multirow[t]{2}{*}{ IMRT } & 238 & 54.1 & & 1.071 & & 1.071 & & 1.071 & \\
\hline & & & & $\begin{array}{l}(0.793- \\
1.447)\end{array}$ & & $\begin{array}{l}(0.793- \\
1.447)\end{array}$ & & $\begin{array}{l}(0.793- \\
1.447)\end{array}$ & \\
\hline $\begin{array}{l}\text { Consolidation } \\
\text { chemotherapy }\end{array}$ & & & 0.852 & & & & & & \\
\hline Yes & 314 & 45.9 & & & & & & & \\
\hline No & 104 & 45.0 & & & & & & & \\
\hline
\end{tabular}


We therefore believed it reasonable to conclude that tumor size and local invasion affected prognosis. To test this hypothesis, we stratified patients diagnosed with 2018 FIGO stage IIIC1 on the basis of T stage (T1/T2/T3) and compared their survival outcomes. Tumor staging for cervical cancer was carried out according to the American Joint Committee on Cancer (Version 9). T1, carcinoma is strictly confined to the cervix; T2, carcinoma invades beyond the uterus but has not extended onto the lower one-third of the vagina or to the pelvic wall; $T 3$, carcinoma involves the lower one-third of the vagina and/or extends to the pelvic wall and/or causes hydronephrosis or nonfun-tcioning kidney [13]. The 5-year OS rates of T1, T2, and T3 were $72.2 \%, 54.1 \%$, and $18.6 \%$, respectively $(P<0.001)$ (Fig. 2 b). There was no significant difference between the 5 year OS rates associated with age, histological type, cell differentiation, type of radiotherapy, minimally invasive surgery, or consolidation chemotherapy (each, $P>0.05$ ). Factors with $P \leq 0.1$ on univariate analysis were included for further multivariate analysis, which revealed that T-stage was an independent prognostic factor associated with survival of patients with stage IIIC1 $(P<0.001)$ (Table 3). Patients with stage IIIC1(T1) experienced longer 5 -year OS compared with those with stages IIIA $(P=0.004)$ or IIIB $(P<0.001)$. Survival of patients with stage IIIC1(T2) was similar compared with patients with stage IIIA $(P=0.522)$ or IIIB $(P=0.133)$. Patients with stage IIIC1(T3) experienced shorter 5-year OS compared with those with stage IIIA or IIIB (each, $P=0.001)$ (Fig. 2c). 
Table 3

Univariate and multivariable analysis for survival in stage IIIC1 cohort

\begin{tabular}{|c|c|c|c|c|c|}
\hline \multirow[t]{2}{*}{ Characteristic } & \multirow[t]{2}{*}{ No. } & \multicolumn{2}{|c|}{ Survival rate (\%) } & \multicolumn{2}{|l|}{ Multivariable } \\
\hline & & 5- year & $P$-value & $\mathrm{HR}(95 \% \mathrm{Cl})$ & P-value \\
\hline Age(years) & & & 0.311 & & \\
\hline$<65$ & 174 & 52.9 & & & \\
\hline$\geq 65$ & 16 & 64.3 & & & \\
\hline Histology & & & 0.228 & & \\
\hline Squamous & 152 & 58.6 & & & \\
\hline Adenocarcinoma & 23 & 55.2 & & & \\
\hline Adenosquamous & 15 & 33.3 & & & \\
\hline Grade & & & 0.745 & & \\
\hline 3 & 37 & 48.9 & & & \\
\hline 2 & 126 & 54.7 & & & \\
\hline 1 & 6 & 55.9 & & & \\
\hline Unknown & 21 & 52.4 & & & \\
\hline T stage & & & $<0.001$ & & $<0.001$ \\
\hline T1 & 87 & 72.2 & & 1 & \\
\hline $\mathrm{T} 2$ & 58 & 54.1 & & $2.189(1.197-4.005)$ & 0.011 \\
\hline T3 & 45 & 18.6 & & $5.085(2.827-9.147)$ & $<0.001$ \\
\hline Tumor size (cm) & & & 0.003 & & 0.015 \\
\hline$<4$ & 87 & 65.9 & & 1 & \\
\hline$\geq 4$ & 103 & 44.1 & & $1.735(1.112-2.70)$ & \\
\hline \multicolumn{6}{|l|}{ Neoadjuvant chemotherapy } \\
\hline Yes & 51 & 61.3 & & & \\
\hline No & 139 & 54.2 & & & \\
\hline Radical hysterectomy & & & $<0.001$ & & 0.054 \\
\hline No & 62 & 34.9 & & 1 & \\
\hline Yes & 128 & 63.5 & & $0.353(0.122-1.018)$ & \\
\hline Minimally invasive surgery & & & 0.159 & & \\
\hline
\end{tabular}




\begin{tabular}{|c|c|c|c|c|c|}
\hline \multirow[t]{2}{*}{ Characteristic } & \multirow[t]{2}{*}{ No. } & \multicolumn{2}{|c|}{ Survival rate (\%) } & \multicolumn{2}{|l|}{ Multivariable } \\
\hline & & 5-year & $P$-value & $\mathrm{HR}(95 \% \mathrm{Cl})$ & $P$-value \\
\hline Yes & 23 & 67.2 & & & \\
\hline No & 167 & 52.4 & & & \\
\hline Radiotherapy & & & 0.084 & & 0.216 \\
\hline 3-DCRT & 88 & 47.8 & & 1 & \\
\hline IMRT & 102 & 56.2 & & $0.751(0.478-1.182)$ & \\
\hline Consolidation chemotherapy & & & 0.469 & & \\
\hline Yes & 147 & 54.9 & & & \\
\hline No & 43 & 51.5 & & & \\
\hline
\end{tabular}

We further investigated the influence of the number of pelvic lymph node metastases (PLNMs) on the prognosis of patients with stage IIIC1p (T1/T2a) undergoing radical hysterectomy and pelvic lymphadenectomy with or without paraortic lymphadenectomy. Metastatic pelvic lymph nodes were evaluated using histopathology. The number of PLNMs per patient ranged between 1 and 9 . The 25th, 50th, and 75th percentiles represented 1,2, and 3 PLNMs, respectively. The median value of the number of PLNMs represents the optimal prognostic cut-off value. The 5-year OS rate of patients with 1 PLNM was $89.1 \%$ vs $47.5 \%$ for those with $>1$ PLNM $(P<0.001)$. Patients with $>2$ PLNMs experienced shorter 5 -year OS rates compared with patients harboring 1 or 2 PLNMs (5-year OS rates, $47.9 \%$ vs $76 \%$, respectively, $P<0.001$ ). The 5 -year OS rates of patients with $>3$ PLNMs were not significantly different from those with 1 to 3 PLNMs (59.3\% vs $65.1 \%$, respectively, $P=0.337)$. Univariate analysis revealed that the survival of patients with IIIC1p(T1/T2a) differed significantly as a function of the number of PLNMs. Thus, the 5-year OS rate of patients with stage IIIC1pN1-2 group was significantly higher compared with IIIC1pN > 2 group (76\% vs $47.9 \%$, respectively, $P<0.001)$ (Fig. 2d). However, age, histology, cell differentiation, type of radiotherapy, and minimally invasive surgery did not have a significant effect on survival (each, $P>0.05$ ) (Table 4). Analysis of multiple factors revealed that the number of PLNMs was an independent risk factor of prognosis. The mortality risk of patients with stage IIIC1pN > 2 was 2.75-fold higher compared with stage IIIC1pN1-2 (HR= 2.753; $95 \%$ Cl: 1.527 to $4.965 ; P=$ 0.001) (Table 4). Patients with stage IIIC1pN1-2 experienced longer 5-year OS rate compared with those with stages IIIA $(P=0.01)$ and IIIB $(P<0.001)$. The 5 -year survival rates of patients with stage IIIC1 pN $>2$ was not significantly different compared with patients with stage IIIA $(P=0.836)$ or IIIB $(P=0.668)$ (Fig. 2e). 
Table 4

Univariate and multivariable analysis for survival in stage IIIC1p (T1/T2a) cohort

\begin{tabular}{|c|c|c|c|c|c|}
\hline \multirow[t]{2}{*}{ Characteristic } & \multirow[t]{2}{*}{ No. } & \multicolumn{2}{|c|}{ Survival rate (\%) } & \multicolumn{2}{|l|}{ Multivariable } \\
\hline & & 5-year & $P$-value & $\mathrm{HR}(95 \% \mathrm{Cl})$ & $P$-value \\
\hline Age (years) & & & 0.266 & & \\
\hline$<65$ & 116 & 62.7 & & & \\
\hline$\geq 65$ & 12 & 79.1 & & & \\
\hline Histology & & & 0.665 & & \\
\hline squamous & 109 & 65.8 & & & \\
\hline other & 19 & 63.2 & & & \\
\hline Grade & & & 0.827 & & \\
\hline G1-2 & 94 & 65.2 & & & \\
\hline G3 & 23 & 60.9 & & & \\
\hline Unknown & 11 & 71.4 & & & \\
\hline T stage & & & $<0.001$ & & 0.001 \\
\hline $\mathrm{T} 1$ & 87 & 75.1 & & 1 & \\
\hline T2a & 41 & 46.5 & & $2.659(1.487-4.755)$ & \\
\hline Lymph node metastasis & & & $<0.001$ & & 0.001 \\
\hline N1-2 & 80 & 76 & & 1 & \\
\hline$N>2$ & 48 & 47.9 & & $2.753(1.527-4.965)$ & \\
\hline Bilateral lymph node metastasis & & & 0.825 & & \\
\hline Yes & 27 & 69.6 & & & \\
\hline No & 101 & 64.4 & & & \\
\hline Tumor size(cm) & & & 0.012 & & 0.059 \\
\hline$<4$ & 66 & 77.4 & & 1 & \\
\hline$\geq 4$ & 62 & 54.1 & & $1.804(0.979-3.323)$ & \\
\hline Neoadjuvant chemotherapy & & & 0.218 & & \\
\hline Yes & 51 & 59.5 & & & \\
\hline No & 77 & 66.5 & & & \\
\hline Minimally invasive surgery & & & 0.364 & & \\
\hline
\end{tabular}

3-DCRT, 3-Dimensional Conformal Radiotherapy; IMRT, Intensity Modulated Radiotherapy 


\begin{tabular}{|c|c|c|c|c|c|}
\hline \multirow[t]{2}{*}{ Characteristic } & \multirow[t]{2}{*}{ No. } & \multicolumn{2}{|c|}{ Survival rate $(\%)$} & \multicolumn{2}{|l|}{ Multivariable } \\
\hline & & 5-year & $P$-value & $\mathrm{HR}(95 \% \mathrm{Cl})$ & $P$-value \\
\hline Yes & 23 & 63.6 & & & \\
\hline No & 105 & 73.9 & & & \\
\hline Radiotherapy & & & 0.937 & & \\
\hline 3-DCRT & 23 & 65.2 & & & \\
\hline IMRT & 105 & 65.5 & & & \\
\hline Consolidation chemotherapy & & & 0.027 & & 0.071 \\
\hline Yes & 111 & 68.3 & & $0.507(0.242-1.060)$ & \\
\hline No & 17 & 47.1 & & 1 & \\
\hline
\end{tabular}

\section{Discussion}

The key findings of the present study are that stage IIIC1 cervical cancer comprises a heterogeneous population with variable prognoses, which significantly differed according to T-stage and the extent of PLNMs. Furthermore, patients with stage IIIC1(T1) or IIIC1 pN1-2 experienced longer survival compared with those with stage IIIA or IIIB.

Convincing evidence indicates that metastatic lymph nodes represents a high-risk factor that negatively affects the prognosis of cervical cancer patients [14-15]. Stage IIIC only includes metastatic lymph nodes, which may overlap or contradict the prognosis of earlier stages. For example, a retrospective study of SEER data for 11733 patients with stage III cervical cancer found that the survival of patients with stage IIIC1 is longer than that of those with stage IIIA or IIIB [16]. Unfortunately, the prognostic outcomes of stage IIIC2 are unknown. Here we show that the 5-year OS rate of patients with stage IIIC2 was significantly lower (23.1\%) and that the mortality risk associated with stage IIIC2 was 3-fold higher compared with stage IIIA.

Although the $2018 \mathrm{FIGO}$ staging system resulted in upward migration of the majority of stages, survival varies among stage III substages [17]. We reasoned that tumor size and local invasion may affect prognosis. We therefore analyzed stage IIIC1 patients according to T stage and found that survival significantly differed according to $\mathrm{T} 1, \mathrm{~T} 2$, and $\mathrm{T} 3$. The 5-year OS rates associated with IIIC1(T1) were significantly higher compared with those of stages IIIA and IIIB, indicating that local tumor factors, as well as nodal status, are important determinants of survival. These results suggest that the influence of the primary tumor is at least or more important than metastasis. The 5-year DFS for stage IIIA/IIIB cervical cancer was only $45 \%$. Concurrent chemoradiotherapy is the standard treatment for locally advanced cervical cancer. Optimise external radiotherapy and brachytherapy in patients with the lower one-third of the vagina and/or extends to the pelvic wall involvement is very impotent for optimum results[18]. Another study found that lymph node metastases negatively affect prognosis according to T stage. In T1B, the effect of stage IIIC2 was most pronounced. 
Furthermore, for T3, the effect was significantly reduced for IIIC2. Within T1B, there is no difference in survival associated with stage IIIC1 for the lower T stages (IB1-2) [19]. Nomograms developed in another study achieve significant prognostic power and are more comprehensive for predicting survival outcomes compared with existing staging criteria such as tumor size, lymph node metastasis, and pelvic wall involvement [20]. Patients with stage IIIC1 have varying prognoses according to tumor size and local invasion and the prognoses of certain patients are better compared with those with stages IIIB or IIIA, indicating that the prognosis of a high stage is better than a low stage. In clinical practice, 2018 FIGO stage IIIC1 requires inclusion of $\mathrm{T}$ staging to effectively guide clinical management and predict prognosis.

In contrast, patients with cervical cancer with PLNMs exhibit different risk profiles, mainly because of additional variables such as bilateral presentation and the number of lymph nodes [21-22]. A comparison of the prognostic accuracies of lymph node staging systems (2018 FIGO, metastatic lymph node ratio, number, and the log-odds of lymph nodes metastasis) shows that the number of lymph node metastasis system is the most accurate for predicting the prognosis of patients with lymph node metastasis after radical operation [23]. The present study establishes that the number of positive pelvic lymph nodes is a better predictor of prognosis of patients with stage IIIC1p (T1/T2a) cervical cancer after they undergo radical surgery. The prognosis of such patients with > 2 lymph node metastases was significantly worse, which is consistent with the findings of other retrospective studies [24]. The researchers found that the prognostic value of PLNMs of cervical cancer patients who underwent radical surgery and chemoradiotherapy, is associated with PLNMs $>3$, nonsquamous cell carcinoma, and lymphatic vascular invasion [25]. These findings suggest that the number of lymph nodes metastasis system may serve to stratify risk groups of recurrence associated with surgically resected cervical cancer exhibiting high-risk factors.

The limitations of the present study include its retrospective design and small sample size of some of the patient groups, which may introduce bias. Furthermore, some patients did not undergo PET-CT, which may affect the diagnosis of lymph node metastasis. We therefore recommend conducting large multicenter analyses to support our findings that argue for revising the 2018 FIGO staging system.

In conclusion, our present model facilitates better stratification of patients' prognoses and emphasizes the independent roles of primary and locoregional disease. These findings suggest that the extent of local tumor invasion is as important as lymph node metastasis, which affects prognosis, and that $\mathrm{T}$ and $\mathrm{N}$ are independent factors affecting prognosis. Furthermore, our present results serve as a potentially important guide for implementing optimal clinical treatment to manage patients with stage IIIC1 cervical cancer. The existing 2018 FIGO staging system may limit its clinical utility, and the available tools require optimization. We therefore assume that stage IIIC1 will be restaged according to T stage, considering tumor size, local tumor invasion, and the presence of lymph nodes.

\section{Declarations}

Acknowledgments We thank Ms. Qiaoling Li for contributing to the statistics analysis.

Author contributions Conceptualization: Xingtao Long,Qi Zhou; data curation: Xingtao Long,Jingshu Liu; formal analysis: Dongling Zou; writing-original draft: Xingtao Long; writing-review \& editing: all 
authors;investigation: all authors; methodology: Xingtao Long; formal analysis:Dongling Zou; project administration: Qi Zhou; software: Dong Wang; language editor:Jingshu Liu,Yuemei Chen.

Funding The present study was supported by the Science and Health Joint Medical Research Project of Chongqing (2019MSXM007, Yuemei Chen); Beijing Kanghua Foundation for the Development of Traditional Chinese and Western Medicine "Le foundation"(KH-2020-LJJ-044,Xingtao Long )

Competing interests The authors declare that they have no conflict of interests.

Availability of data and material In accordance with the journal's guidelines, we will provide our data for the reproducibility of this study in other centers if such is requested.

Ethics approval The study was approved by the ethics committee of Chongqing University Cancer Hospital, Chongqing, China ( project number: 2019[177]).

Consent to participate Informed consent for using medical information for scientific purposes was obtained from all subjects.

\section{References}

1. Arbyn M, Weiderpass $E$, Bruni $L$, et al (2020) Estimates of incidence and mortality of cervical cancer in 2018: a worldwide analysis. Lancet Glob Health 8:e191-e203

2. Chen WQ, Li H, Sun KX, et al (2018) Report of Cancer Incidence and Mortality in China, 2014. Zhonghua Zhong Liu Za Zhi 40:5-13

3. Odicino F, Pecorelli S, Zigliani L, et al (2008) History of the FIGO cancer staging system. Int J Gynaecol Obstet 101:205-210

4. FIGO Committee on Gynecologic Oncology ( (2014) FIGO staging for carcinoma of the vulva, cervix, and corpus uteri. Int J Gynaecol Obste 125:97-98

5. Benedet JL, Bender $\mathrm{H}$, Jones $\mathrm{H}$, et al (2000) FIGO staging classifications and clinical practice guidelines in the management of gynecologic cancers. Int J Gynaecol Obstet 70:209-262

6. Ward ZJ, Grover S, Scott AM, et al (2020) The role and contribution of treatment and imaging modalities in global cervical cancer management: survival estimates from a simulation-based analysis. Lancet Oncol 21:1089-1098

7. Li S, Li X, Zhang Y, et al (2016) Development and validation of a surgical-pathologic staging and scoring system for cervical cancer. Oncotarget 7:21054-21063

8. Bhatla N, Berek J.S, Cuello Fredes M, et al (2019) Revised FIGO staging for carcinoma of the cervix uteri. Int J Gynaecol Obstet 145:129-135

9. Alvarez RD, Soong SJ, Kinney WK, et al (1989) Identification of prognostic factors and risk groups in patients found to have nodal metastasis at the time of radical hysterectomy for early-stage squamous carcinoma of the cervix.Gynecol Oncol 35:130-135

10. Salvo G, Odetto D, Pareja R, et al (2020) Revised 2018 International Federation of Gynecology and Obstetrics (FIGO) cervical cancer staging: A review of gaps and questions that remain. Int J Gynecol 
Cancer 30:873-878

11. Wright JD, Matsuo K, Huang Y, et al (2019) Prognostic Performance of the 2018 International Federation of Gynecology and Obstetrics Cervical Cancer Staging Guidelines. Obstet Gynecol 134:49-57

12. Kato T, Takashima A, Kasamatsu T,et al (2015) Gynecologic Oncology Study Group of the Japan Clinical Oncology Group. Clinical tumor diameter and prognosis of patients with FIGO stage IB1 cervical cancer (JCOG0806-A).Gynecol Oncol 137:34-39

13. Olawaiye AB, Baker TP, Washington MK, et al (2021) The new (Version 9) American Joint Committee on Cancer tumor, node, metastasis staging for cervical cancer. CA Cancer J Clin. 30. doi: 10.3322/caac.21663.

14. Narayan K, Fisher RJ, Bernshaw D,et al (2009) Patterns of failure and prognostic factor analyses in locally advanced cervical cancer patients staged by positron emission tomography and treated with curative intent. Int J Gynecol Cancer 19:912-918

15. Singh N, S. Arif (2004) Histopathologic parameters of prognosis in cervical cancer-a Review. Int J Gynecol Cancer 14:741-750

16. Matsuo K, Machida H, Mandelbaum RS, et al (2019) Validation of the 2018 FIGO cervical cancer staging system. Gynecol Oncol 152:87-93

17. Grigsby PW, Massad LS, Mutch DG et al FIGO 2018 staging criteria for cervical cancer: Impact on stage migration and survival.Gynecol Oncol 2020;157:639-643

18. Chopra S, Gupta M, Mathew A, et al (2018) Locally advanced cervical cancer: a study of 5-year outcomes.Indian J Cancer 55(1):45-49

19. McComas KN, Torgeson AM, Ager BJ, et al (2020) The variable impact of positive lymph nodes in cervical cancer: Implications of the new FIGO staging system. Gynecol Oncol 156:85-92

20. Yang X, An J, Zhang Y, et al (2020) Prognostic Nomograms Predicting Survival in Patients With Locally Advanced Cervical Squamous Cell Carcinoma: The First Nomogram Compared With Revised FIGO 2018 Staging System. 10:591700

21. Guo Q, Jun Zhu, Ke G,et al (2020) Validation of the prognostic value of various lymph node staging systems for cervical squamous cell carcinoma following radical surgery: a single-center analysis of 3,732 patients. Annals of translational medicine 8:485

22. Cea García J, Rodríguez Jiménez I, Ríos-Pena L,et al (2020) Incidence and univariate models for lymphatic drainage disorders following management for cervical cancer. J Obstet Gynaecol Res 15

23. Guo Q, Zhu J, Wu Y, et al (2020) Comparison of different lymph node staging systems in patients with node-positive cervical squamous cell carcinoma following radical surgery. J Cancer 11:7339-7347

24. Pedone Anchora L, Carbone V, Gallotta V, et al (2020) Should the Number of Metastatic Pelvic Lymph Nodes be Integrated into the 2018 Figo Staging Classification of Early Stage Cervical Cancer? Cancers (Basel) 12:1552

25. Kwon J, Eom KY, Kim YS, et al (2018) The Prognostic Impact of the Number of Metastatic Lymph Nodes and a New Prognostic Scoring System for Recurrence in Early-Stage Cervical Cancer with High Risk Factors: A Multicenter Cohort Study (KROG 15 - 04). Cancer Res Treat 50:964-969 
Figures

Patients with cervical cancer

Inclusion criterias between January

2011 to December 2014.

$$
(\mathrm{N}=503)
$$

\begin{tabular}{|l|l|}
\hline \\
Included cases \\
$\mathrm{N}=418 ; 42$ for stage IIIA,120 for stage III \\
IIIC2.
\end{tabular}

Figure 1

Flowchart of the protocol for the patients' screening and recruitment 
A

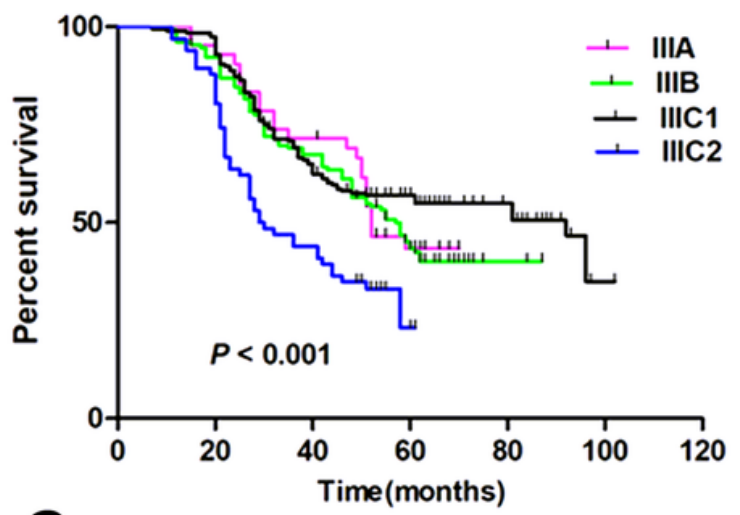

C

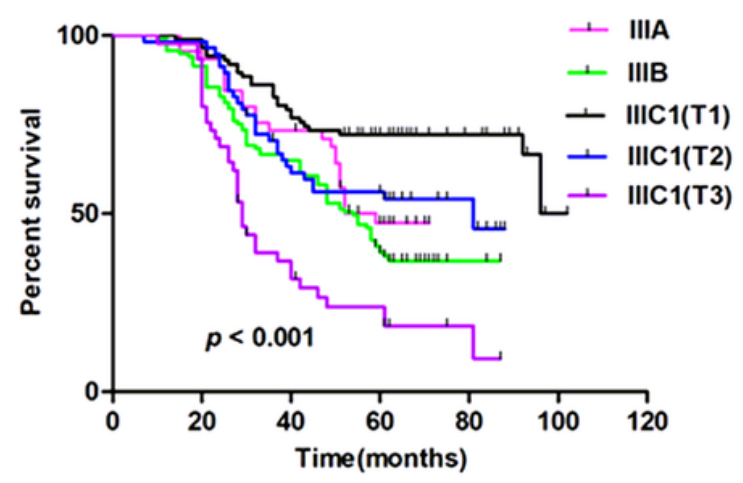

E

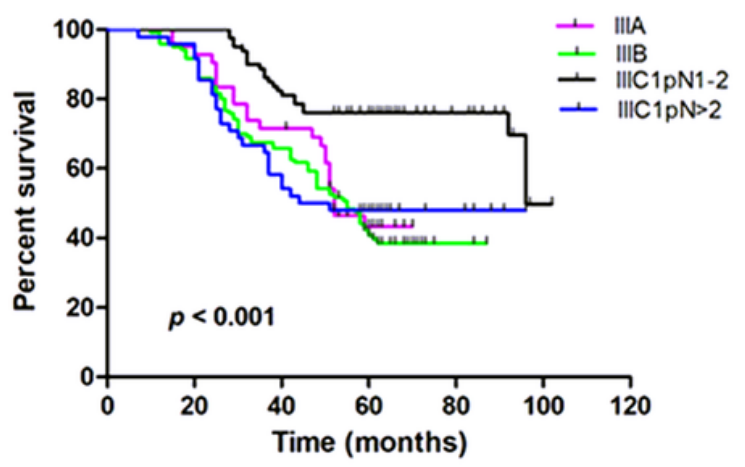

B

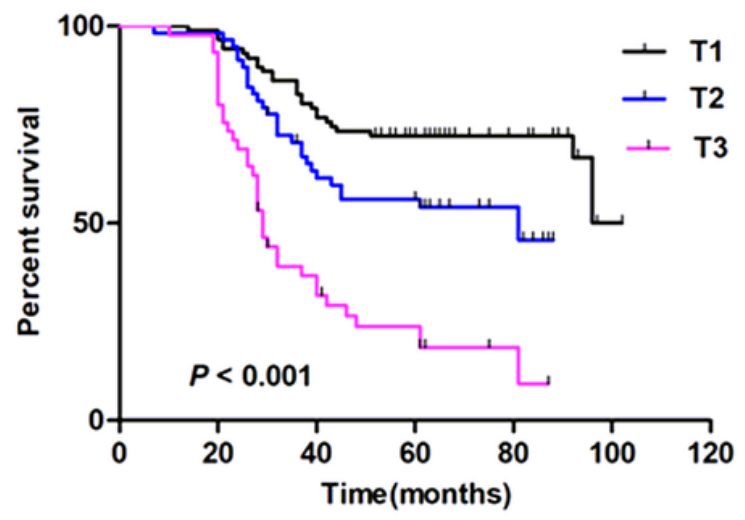

D

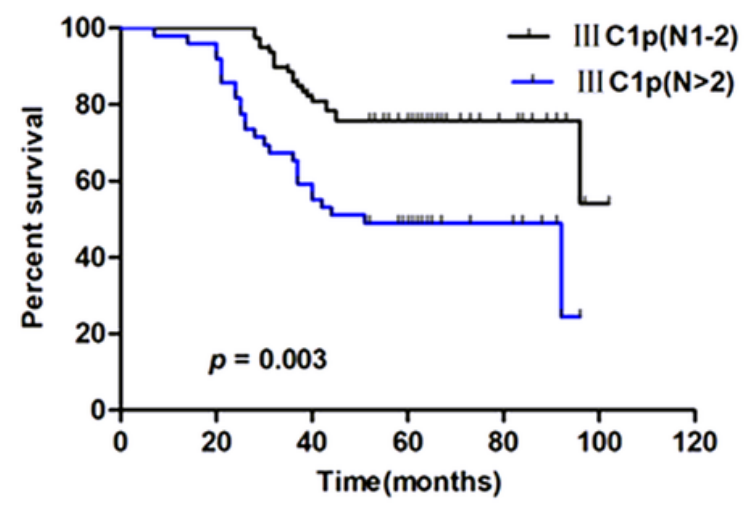

Figure 2

Kaplan-Meier curves based on 2018 FIGO cancer staging system. Log-rank test for P-values.Survival is shown for (a) stage III cervical cancer, (b) stage IIIC1 cervical cancer, (c) stage IIIC1 cervical cancer based on T-stage, (d) stage IIIC1p (T1/T2a) cervical cancer, and (e) stage IIIC1 cervical cancer based on the number of metastatic pelvic lymph nodes 